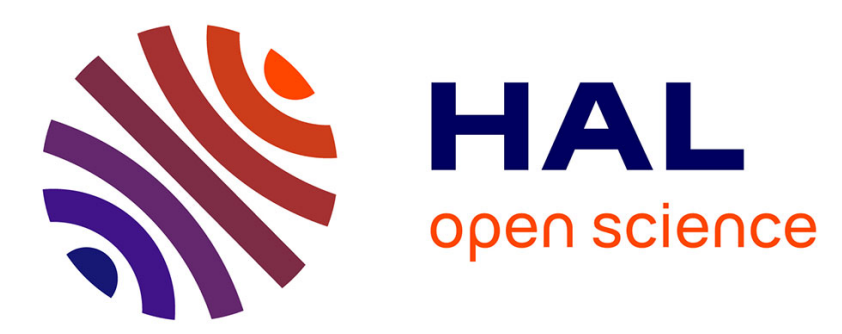

\title{
Structural evolution of Ni3Al-based intermetallic compounds during tensile or cold-rolling deformations
}

\author{
M. Viltange, O. Dimitrov
}

\section{To cite this version:}

M. Viltange, O. Dimitrov. Structural evolution of Ni3Al-based intermetallic compounds during tensile or cold-rolling deformations. Journal de Physique IV Proceedings, 1993, 03 (C7), pp.C7-477-C7-480. 10.1051/jp4:1993777 . jpa-00252197

\section{HAL Id: jpa-00252197 https://hal.science/jpa-00252197}

Submitted on 1 Jan 1993

HAL is a multi-disciplinary open access archive for the deposit and dissemination of scientific research documents, whether they are published or not. The documents may come from teaching and research institutions in France or abroad, or from public or private research centers.
L'archive ouverte pluridisciplinaire HAL, est destinée au dépôt et à la diffusion de documents scientifiques de niveau recherche, publiés ou non, émanant des établissements d'enseignement et de recherche français ou étrangers, des laboratoires publics ou privés. 


\title{
Structural evolution of $\mathrm{Ni}_{3} \mathrm{Al}$-based intermetallic compounds during tensile or cold-rolling deformations
}

\author{
M. VILTANGE and O. DIMITROV
}

CECM, CNRS, 15 nue Georges Urbain, 94407 Vitry-sur-Seine cedex, France

\begin{abstract}
The influence of plastic deformation on the evolution of long-range ordered (LRO) intermetallic compounds was investigated in boron-doped $\mathrm{Ni} 76 \mathrm{Al}_{24}$ and $\mathrm{Ni}_{6} \mathrm{Al}_{20} \mathrm{Ti} 4$. Electrical resistivity measurements were used to evaluate (a) the modifications of cristallographic order due to the production of lattice defects and (b) the modifications of chemical order due to disordering induced by the deformation. An analytical relationship was established to represent these two contributions to the resistivity changes. Its application to the results of cold-rolling experiments shows that disordering by deformation is much less effective in these long-range ordered materials than in a previouly investigated short-range ordered alloy.
\end{abstract}

\section{INTRODUCTION}

In ordered alloys, plastic deformation affects the microstructure by :

(a) introducing lattice defects,

(b) decreasing atomic order: the neighbourhood of a given atom is modified during dislocation glide.

Electrical resistivity, which is sensitive to all deviations from a periodic lattice, was used to detect such modifications in two long-range ordered (LRO) Ni3 Al-based materials.

\section{EXPERIMENTAL}

The investigated materials consisted of two substoichiometric intermetallic compounds, $\mathrm{Ni}_{75.8} \mathrm{Al}_{24.2}$ and $\mathrm{Ni}_{76} \mathrm{Al}_{20} \mathrm{Ti}_{4}$. They were prepared from high-purity metals by plasmafurnace melting (1), with a ductilizing addition of 0.1 weight per cent boron. The samples were annealed for $5 \mathrm{~h}$ at $1273 \mathrm{~K}$, then furnace-cooled to obtain a reproducible atomic structure (standard anneal) of resistivity $\rho_{\mathrm{N}}$.

Deformation was performed by extension at $77 \mathrm{~K}$ or at room temperature (RT) for $\mathrm{Ni}_{66} \mathrm{Al}_{24}$, and by cold-rolling at $\mathrm{RT}$ for both materials.

Two procedures were used for the electrical resistivity measurements:

i) Measurements were performed at $4.2 \mathrm{~K}$ before and after the deformation, then after a second standard anneal which restores the initial atomic structure: the change in resistivity due to the plastic deformation $\Delta \rho$ pl. and the effective deformation can thus be obtained.

ii) During tensile deformation, the changes of electrical resistance were continuously recorded, allowing a determination of the changes in resistivity due to the elasto-plastic deformation $\Delta \rho \mathrm{el}+\mathrm{pl}$. 


\section{RESULTS}

The resistivity variations resulting from small deformations by extension or by rolling are shown in Figure 1. The presented tensile deformation data were obtained by procedure i) above; procedure ii) lead to very similar results. It can be seen that the curves have similar shapes but with higher increments of resistivity in the case of coldrolling. A decrease of deformation temperature from $\mathrm{RT}$ to $77 \mathrm{~K}$ does not result in a large difference of the resistivity change.

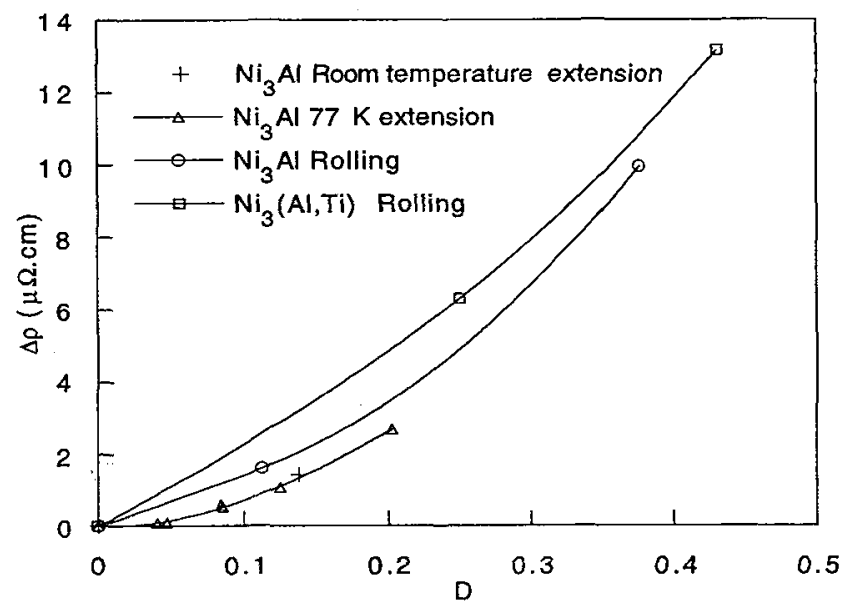

Figure 1. Resistivity increments produced by small tensile ( $D=\ln 1 / 1_{0}, 1=$ sample length) or rolling $\left(\mathrm{D}=\ln \mathrm{e}_{0} / \mathrm{e}, \mathrm{e}=\right.$ sample thickness) deformations.

The case of high deformations by cold-rolling is shown in figure 2 for the two intermetallic compounds. The partial substitution ot aluminium by titanium has only a small effect on the resistivity changes.

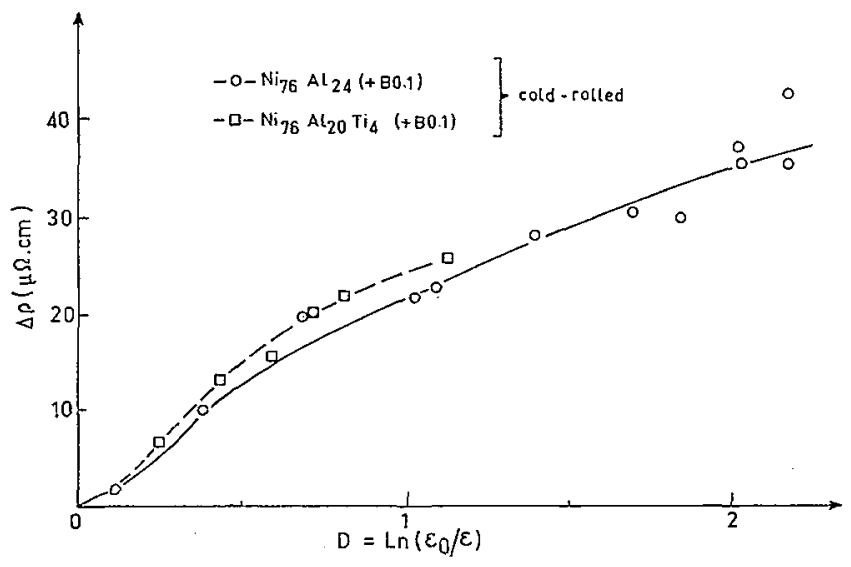

Figure 2. Resistivity increments produced by large rolling deformations.

The measured resistivity variations $\Delta \rho$ were analysed by considering the contribution of the produced defects, $\Delta \rho$ def, and that of the change in atomic order, $\Delta \rho_{\text {order: }}$ :

$\Delta \rho=\Delta \rho$ def $+\Delta \rho_{\text {order }}$ 
- $\Delta \rho$ def was assumed to be proportional to the deformation $D,\left(\Delta \rho_{\text {def }}=A . D\right)$, like in pure metals. In the case of cold-rolled nickel (2), $A$ is equal to $0.09 \mu \Omega \mathrm{cm}$ up to $\mathrm{D} \sim 2$.

- the resistivity due to the atomic order porder is related to the degree of LRO, S by (3):

$$
\text { porder }=\rho \text { dis. }\left(1-S^{2}\right) /\left(1-a . S^{2}\right)
$$

where $\rho$ dis is the resistivity of the totally disordered compound and a ( 0.75 for $\mathrm{Ni3} A \mathrm{Al})$ is a coefficient depending of the electronic structure.

Assuming disordering due to dislocation glide to be proportional to the existing amount of order (dS $/ \mathrm{dD}=-\mathrm{C} . \mathrm{S}$ ) leads to :

$$
\Delta \rho_{\text {order }}=\rho^{\circ} \text { order } \cdot[1-\exp (-2 \text { C.D })] /[1-\text { a.exp }(-2 \text { C.D })]
$$

with $\rho^{\circ}$ order $=\rho_{\text {dis }}-\rho_{N}$.

A fit of equation [1] to the changes of resistivity of $\mathrm{Ni}_{75.8} \mathrm{Al}_{24.2}$ is shown in figure 3 , together the two individual contributions $\Delta \rho$ def and $\Delta \rho$ order. The equation is seen to adequately represent the data at large deformations $(D>0.5)$, but not at small deformations (fig.2), where a positive curvature is found.

The values obtained for the coefficients $A$ and $C$ in the two compounds are given in the Table 1.

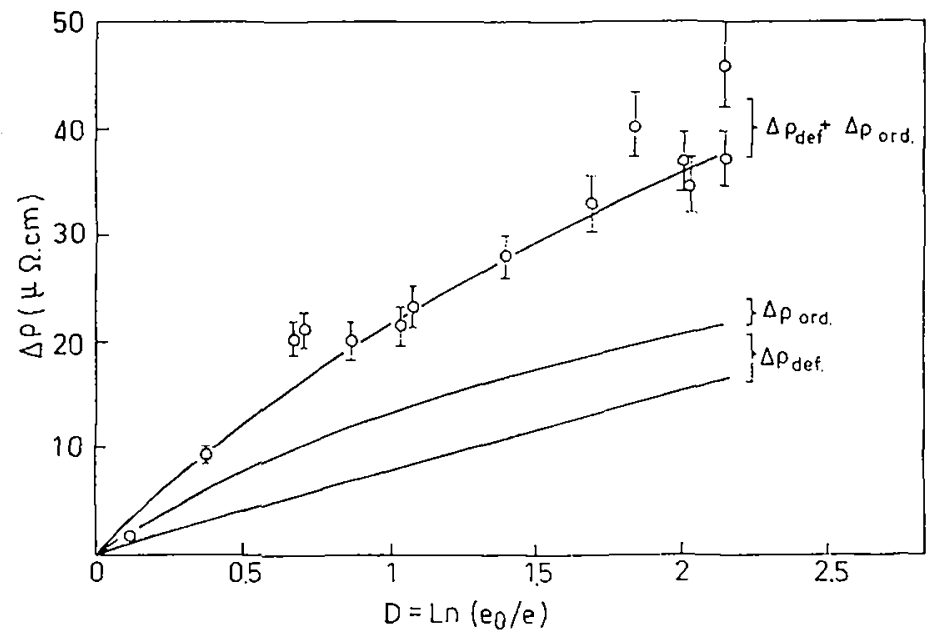

Figure 3. Fit of equation [1] to the data of cold-rolled $\mathrm{Ni}_{75.8} \mathrm{Al}_{24.2}$

\begin{tabular}{|c|c|c|c|c|c|c|}
\hline & \multicolumn{3}{|c|}{$\begin{array}{c}\text { Resistivity values } \\
\text { of undoped alloys } \\
(\mu \Omega \mathrm{cm})\end{array}$} & $\begin{array}{c}\text { Resistivity values } \\
\text { of B-doped alloys } \\
(\mu \Omega \mathrm{cm}) \\
\rho_{\mathrm{N}}\end{array}$ & $\begin{array}{c}\rho^{\circ} \text { order } \\
(\mu \Omega \mathrm{cm})\end{array}$ & $\mathrm{C}$ \\
\hline $\mathrm{Ni75.8} \mathrm{Al}_{24.2}$ & $\begin{array}{c}\rho_{\text {dis }} \\
\text { (from data } \\
\text { of ref. 4) }\end{array}$ & 6.8 & 31.70 & 21.90 & 9.1 & 0.07 \\
\hline $\mathrm{Ni}_{76} \mathrm{Al}_{20} \mathrm{Ti}_{4}$ & 47.02 & $\begin{array}{c}23.47 \\
\text { (ref. 5) }\end{array}$ & 23.55 & $\begin{array}{c}38.44 \\
(\text { ref. 6) }\end{array}$ & 11.5 & 0.14 \\
\hline
\end{tabular}

Table 1. Resistivity values used in the fit of equation [1] to the experimental data, and resulting $A$ and $C$ coefficients. 


\section{DISCUSSION}

1. The $\Delta p$ (D) plots exhibit a positive curvature in the range of small deformations, whereas the model of eq.[1], based on a constant disordering efficiency, predicts the reverse trend. This points to a low efficiency of disordering during the initial stages of dislocation glide.

2. In the same deformation range, the resistivity increments produced by extension are substantially smaller than the ones due to cold-rolling. This might be related to the more complex deformation process during rolling, or to a possible glide localization during the tensile deformation.

3. The effect of a partial substitution of $\mathrm{Al}$ by $\mathrm{Ti}$ is not very strong. It consists in an increase of both contributions to the resistivity increment, reflected in somewhat larger values of the $A$ and $C$ parameters.

4. The deformation of the present LRO materials leads to very different results from those of a previously investigated short-range ordered (SRO) $\mathrm{Fe}_{40} \mathrm{Cr}_{17} \mathrm{Ni}_{43}$ alloy (7):

- the defect resistivity coefficient $A$ is much larger $(\sim 10 \mu \Omega \mathrm{cm})$ than in the SRO

alloy $(0.50 \mu \Omega \mathrm{cm})$ and in pure metals $(0.09 \mu \Omega \mathrm{cm}$ for $\mathrm{Ni})$. This is probably mainly due to a higher sensitivity of resistivity to deviations from a periodic lattice, which also leads to high values of the Frenkel-pair resistivity and of the ideal (phonon) resistivity.

- the disordering coefficient $C$ is much smaller ( 0.1) than in the SRO alloy (1.18) so that long-range order is destroyed much more slowly than short-range order: the efficiencies of disordering induced by deformations are extremely different. In all cases, the slip of a dislocation of the basic lattice creates disorder. However, in LRO materials, order is restored by the slip of a second dislocation in the same glide plane : there is almost no disordering at small deformations. Disordering is really effective when the slip mechanism becomes more complex, when, for instance, dislocation cross-slip is activated.

\section{CONCLUSION}

Electrical resistivity is a simple and effective tool to characterize the deformation of ordered compounds. It leads to a determination of defect production coefficients and to an evaluation of the disordering efficiency; the latter is found to be much smaller in LRO than in SRO alloys. The comparison of samples deformed by extension or by rolling shows that the latter process produces larger effects. The substitution, in $\mathrm{Ni}_{3} \mathrm{Al}$, of a part of aluminium by titanium has only a small influence in terms of both defect production and disordering.

\section{REFERENCES}

(1) X. Zhang, Doctor's Thesis, Caen University, 1989

(2) P. Merklen, Doctor's Thesis, Paris University, 1968

(3) P.L. Rossiter, J. Phys. F : Metal Phys. 10 (1980), 459

(4) B. Sitaud, O. Dimitrov, J.Phys.: Condens. Matter 2 (1990) 7061

(5) C. Minot, Report CECM 91A1 (1991).

(6) M.Tassin, Report CECM 92A2 (1992)

(7) M. Viltange, O. Dimitrov, J. Nucl. Mater. 185 (1991) 50 